\title{
El uso de Sistemas de Información Geográfica para el estudio de los sucesos de la Patagonia Rebelde en el noreste de Santa Cruz
}

Miguel Á. Zubimendi*

Recibido:

27 de septiembre de 2017

Aceptado:

27 de noviembre de 2017

\section{Resumen}

En el marco de un proyecto de investigación que busca la recuperación del patrimonio rural del noreste de Santa Cruz se ha construido un Sistema de Información Geográfica (SIG) y una base de datos documental que pretende integrar toda la información existente sobre la huelga de peones rurales ocurrida a fines del año 1921 -conocida comúnmente como "La Patagonia Rebelde"- en el territorio de dicha provincia. Esta huelga fue un hecho que marcó de forma significativa la historia de Santa Cruz, principalmente debido a la brutal represión emprendida por el Ejército Argentino que conllevó la muerte y fusilamiento de cientos de peones rurales. En este trabajo se presenta la metodología empleada en la construcción de dicho SIG y la base de datos documental, explicando las fuentes (mapas, documentos, manuscritos, etc.) que se utilizaron. Posteriormente, se presentan algunos ejemplos de la aplicación del SIG para la construcción de cartografías temáticas y reconstrucciones de, por ejemplo, el movimiento de algunos de los actores principales de estos trágicos sucesos. El empleo de las herramientas y metodologías de la arqueología espacial permitió avanzar en el conocimiento de cómo la huelga afectó el noreste de Santa Cruz, en especial su extensión y el accionar de algunos de los actores involucrados.

\section{The use of Geographical Information Systems in the study of the Patagonia Rebelde strike in Northeastern Santa Cruz}

\begin{abstract}
Within the framework of a research project that aims to recover the rural heritage of Northeastern Santa Cruz, a Geographical Information System (GIS) and a documentary database have been built to integrate all existing information on the rural strike of the year 1921 — commonly known as "La Patagonia Rebelde" — which broke out within the territory of this Province. This strike was a significant event in the history of Santa Cruz territory, mainly because of the brutal repression undertaken by the Argentine
\end{abstract}

Palabras clave

La Patagonia Rebelde Huelga de 1921 SIG

Base de datos documental

\section{Keywords}

Patagonia Rebelde

The 1921 strike

GIS

Documental database 
1. Esta denominación común surge a partir de la película de Héctor Olivera estrenada en el año 1974 basada en los libros de Osvaldo Bayer, que se llamaban originalmente "Los Vengadores de la Patagonia Trágica". Posteriormente, a partir de la década de 1990, los libros se reeditaron bajo el título " $\mathrm{La}$

Patagonia Rebelde”. De esta forma, a partir de la publicación de estas obras se pasó a denominar como Patagonia Rebelde a todo el movimiento huelguista de los años 1920 y 1921 en el territorio de Santa

Cruz y a la posterior represión salvaje emprendida por el Ejército Argentino.
Army, which led to death and execution of hundreds of striking rural labourers. This article presents the methodology used in the construction of this GIS and documentary database, explaining the sources (maps, documents, manuscripts, etc.) that were used. Subsequently, we present some case-studies of this GIS application, including the construction of thematic cartographies and reconstructions of the movements of some of the main actors of the strike. Finally, we believe that the use of spatial archaeology tools and methodologies has revealed new data on how the strike affected Northeastern Santa Cruz, especially the extent of the strike and the actions of some of the actors involved.

\section{Introducción}

Desde hace más de 15 años que un equipo interdisciplinario de investigación, formado por historiadores, arquitectos y licenciados en turismo de la Unidad Académica Caleta Olivia de la Universidad Nacional de la Patagonia Austral, tiene como objeto conocer la historia y el patrimonio cultural del noreste de la provincia de Santa Cruz, en especial, en relación con el mundo rural. Con el tiempo, se han ido sumando otros especialistas provenientes de la arqueología, los medios audiovisuales y la economía. Las investigaciones se han centrado particularmente en la primera mitad del siglo $\mathrm{XX}$, cuando la ganadería ovina constituía la principal actividad económica. En estas investigaciones se pretende rescatar, recuperar y revalorizar el mundo rural como parte del patrimonio cultural de la zona, tanto como actividad económica vinculada con el turismo mediante la definición de circuitos turísticos, como desde la interacción con distintos actores sociales y políticos que requieren apoyo desde el punto de vista patrimonial (municipalidades, comisiones de fomento, etc.). Con relación al mundo rural de comienzos del siglo XX en Santa Cruz, las huelgas de peones rurales -en especial la segunda que ocurrió en el año 1921 y es conocida popularmente como "La Patagonia Rebelde"1 - constituyen un hito de referencia en la memoria colectiva. Si bien no fue uno de los objetivos iniciales del proyecto, al analizar el mundo rural resultó que las huelgas de comienzos de la década de 1920 son insoslayables y a lo largo de los años fueron abarcadas de distintas formas dentro del equipo de investigación (Sampaoli et al., 2014; Tagliorette et al., 2016).

En abril de 2013, autoridades de la Universidad Nacional de la Patagonia Austral y del Archivo Nacional de la Memoria llegaron a un acuerdo para desarrollar un trabajo conjunto en pos de localizar las tumbas colectivas que pudieran existir como consecuencia de la represión y el fusilamiento de peones por parte del Ejército Argentino en la provincia de Santa Cruz. En el marco del "Protocolo de Investigación para la Ubicación de Cuerpos de Peones Rurales Fusilados en Santa Cruz durante las Huelgas Rurales de 1921" se iniciaron trabajos en tres zonas de la provincia: uno que analizaría el sur, otro que debía realizar lo propio en el centro provincial y un tercero vinculado al noreste de Santa Cruz. De esta forma, el equipo de investigación comienza a trabajar en conjunto con el Archivo Nacional de la Memoria desde septiembre de 2014 para localizar la fosa común en el denominado Cañadón de los Muertos ubicado cerca de la localidad de Jaramillo en el departamento Deseado, donde fue fusilado el líder huelguista de la zona norte, José Font, conocido como Facón Grande, junto a un número no determinado de otros huelguistas (Zubimendi, Sampaoli y Tagliorette, en prensa). La recuperación de estos lugares donde fueron asesinados peones rurales atendía no tanto a su relevancia por el número de fusilados -menor que el registrado en el sur de Santa Cruz- sino debido a que la ubicación exacta de la misma se ha perdido en la memoria colectiva de los actuales habitantes de este territorio. Además, es en esta zona donde ocurre el único enfrentamiento armado entre los huelguistas y el Ejército 
Argentino, en la Estación Tehuelches del Ferrocarril Nacional Patagónico, y finalizan las acciones del Ejército a comienzos del año 1922, dando por terminada la huelga y la "pacificación" del territorio a mediados de enero de dicho año. También en el año 2014 se inició un proyecto en el marco del Programa de cooperación Binacional con Italia SECyT - IMAE 2014-2016 denominado "Nueva Tecnología y Patrimonio Poniendo en Valor Paisajes Culturales en Santa Cruz. Una Experiencia de Cooperación Entre Italia y Argentina", entre la Unidad Académica Caleta Olivia de la Universidad Nacional de la Patagonia Austral y la Università Politecnica delle Marche (Ancona, Italia). El objetivo de este último era aplicar diferentes tecnologías y enfoques para precisar la ubicación exacta de la tumba del Cañadón de los Muertos de Jaramillo, así como otros lugares relacionados con la huelga, en especial aquellos donde ocurrieron asesinatos de huelguistas en todo el noreste de Santa Cruz. Interesa particularmente la ubicación del último campamento que ocuparon en el denominado Cañadón del Carro, desde donde se entregan a las tropas del Ejército Argentino y parte de ellos son fusilados y enterrados en el Cañadón de los Muertos de Jaramillo.

De esta forma, en los últimos años, el equipo de investigación ha comenzado a trabajar activamente en la recuperación de la memoria y la ubicación de diferentes hitos de la huelga de peones rurales en el noreste de Santa Cruz. Asimismo, se han realizado actividades conjuntas con distintos niveles estatales (Archivo Nacional de la Memoria, Comisión de Fomento de Fitz Roy y Jaramillo, entre otros) tendientes a la puesta en valor del patrimonio rural y recuperar la memoria de estos trágicos sucesos (Tagliorette et al., 2016) que constituyeron un elemento vertebrador de la sociedad de este territorio, a pesar de los silencios impuestos al mismo con posterioridad a los hechos (Bayer, 1974). En este artículo, en particular, se presenta la metodología de trabajo para la construcción de un Sistema de Información Geográfica (SIG) y una base de datos documental, aplicados a la problemática de La Patagonia Rebelde y, a modo de ejemplo, algunos de los resultados parciales que hemos logrado en los últimos años. Finalmente, se brinda una reflexión sobre la aplicación de un SIG y metodologías de la arqueología espacial a problemáticas históricas que permiten ampliar el conocimiento de los sucesos de la huelga del año 1921 y su vinculación con la patrimonio, la construcción de la identidad local y su potencia para transformarlo en un activo económico mediante la generación de circuitos turísticos que integren a las comunidades donde se desarrollaron estos trágicos sucesos.

\section{Antecedentes}

\section{El noreste de Santa Cruz hacia 1921}

En cuanto al poblamiento del noreste de Santa Cruz al momento de la huelga de 1921, este estaba condicionado por el proceso de integración nacional ocurrido a fines del siglo XIX. En este sentido, luego de la llamada Conquista del Desierto y el exterminio $\mathrm{o}$ arrinconamiento de las poblaciones aborígenes originarias, el Estado Nacional dispuso de las tierras de la Patagonia y su uso para la ganadería extensiva, para lo cual se implementó un mecanismo de otorgamiento de tierras a personas que estuvieran dispuestas a radicarse en el territorio. Mediante la Ley № 1532 de organización de los Territorios Nacionales se proporcionaron los fundamentos para la ocupación de Patagonia y de vastas extensiones de tierras. Este proceso se inició al sur del territorio de Santa Cruz, donde el arrendamiento de tierras fue la forma más común de acceder a los lotes (Barbería, 2001), sin embargo, en el noreste fue más frecuente la ocupación de hecho por parte de particulares, en su mayoría con muy poco capital y ganado ovino.

La escasez de agua -especialmente grave en el noreste de Santa Cruz y la costa cercana al golfo San Jorge-, los fuertes vientos del Oeste y el riguroso clima imperante, hicieron 
que las viviendas de las estancias se ubicaran cerca de vertientes naturales, recostadas en las laderas de las mesetas o protegidas en los cañadones. Las construcciones en las estancias del noreste de la provincia hacia la década de 1920 se caracterizaban por su simpleza y sencillez, y las vías de comunicación terrestre eran pequeñas huellas vecinales que unían a los distintos poblados y las estancias ubicadas en el interior. El acceso al sector, desde el Norte, estaba dado por una huella de carros precariamente trazada que unía los pueblos de Comodoro Rivadavia y Caleta Olivia. A su vez, parte de las cargas y los pasajeros se movilizaban por barco, parando en los diversos puertos de la zona, tales como Mazarredo, Cabo Blanco, Bahía Laura y Caleta Olivia (Ciselli, 1999; Ibarroule, Tagliorette y Sampaoli, 2011). El ferrocarril que unía los poblados de Puerto Deseado y Las Heras era otra vía de comunicación de importancia, ya que conectaba Puerto Deseado con el interior del territorio.

En términos generales, los establecimientos ganaderos del norte del territorio de Santa Cruz eran de menor extensión que aquellos ubicados en el sur. Además tenían suelos y pasturas más pobres y una menor cantidad de ganado ovino que las estancias del centro y sur. A su vez, para el año 1921 quedaban ya pocos terrenos sin ocupar, en general en las zonas más inaccesibles, con peores pasturas y con menor productividad lanar, como la ubicada al sur del río Deseado (Barbería, 2001; Ciselli, 1999; Ibarroule et al., 2011).

\section{Breve descripción de las huelgas de los años 1920 y 1921}

Desde fines de la década de 1910 el precio de la lana se desplomaba, generando una menor ganancia para los estancieros, lo que conllevó a un endurecimiento de las ya de por sí duras condiciones laborales de los peones y obreros rurales. En este contexto es que la Sociedad Obrera de Río Gallegos y la Federación Obrera (FORA), de tendencia anarquista, propulsaron una campaña de sindicalización de peones y llevaron a cabo una primera huelga en el verano de 1920-1921. Ante esta situación, el gobierno radical de Hipólito Yrigoyen - presionado por Gran Bretaña, preocupada por las inversiones de sus súbditos en la Patagonia- envió en enero de 1921 tropas del ejército al mando del Teniente Coronel Héctor Benigno Varela con la orden de normalizar la situación. En este primer viaje, Varela logró un acuerdo por el cual los terratenientes se comprometían a cumplir con las exigencias de los peones (Bayer, 1972a). Sin embargo, al poco tiempo los estancieros comenzaron a no respetar los acuerdos pactados, lo que junto con el hostigamiento realizado por la policía contra la Sociedad Obrera de Río Gallegos y la Federación Obrera, motivó una nueva declaración de huelga total en todo el territorio en octubre de 1921.

La estrategia seguida por los peones rurales durante la huelga de 1921 consistía en dividirse en grupos, los cuales procedían a desplazarse por las estancias, requisando caballadas, armas y víveres, tomar como prisioneros a los dueños y administradores y como rehenes a los peones que no quisieran plegarse a la huelga. Esta estrategia implicaba una alta movilidad de los grupos para despistar a la policía. De esta forma, el movimiento se extendió desde Río Gallegos por la zona interior del territorio, capitaneados por Antonio Soto; la zona central de San Julián, Puerto Santa Cruz, Paso Ibáñez (actualmente Comandante Luis Piedra Buena) y el interior, bajo el mando de Ramón Outerello y Albino Argüelles; y el norte del territorio, por José Font, conocido como Facón Grande, quien no era un dirigente sindical, sino un carrero cuentapropista que fue buscado por los huelguistas para que los dirija.

Ante la presión ejercida por los dueños de los campos en Santa Cruz, junto con la de varias embajadas extranjeras que defendían los intereses y la integridad de sus ciudadanos que tenían haciendas en el sur, Hipólito Yrigoyen decide enviar nuevamente al Teniente Coronel Héctor Benigno Varela con el Regimiento $10^{\circ}$ de Caballería, compuesto por una tropa de 200 hombres, pero esta vez con diferentes órdenes. Apenas desembarcó 
en el Territorio de Santa Cruz declara la Ley Marcial, imponiendo el fusilamiento de un número variable, de entre 500 y 1.500 peones y obreros rurales durante toda su campaña, la que se extendió hasta enero de 1922 (Bayer, 1972b). Varela y parte de su tropa se concentraron primero en las zonas centro y sur, como las cuencas altas del Coyle, Lago Argentino y desembocadura del río Santa Cruz, hasta aproximadamente el 10 de diciembre, luego de los fusilamientos de la estancia La Anita. Posteriormente, el Capitán Viñas Ibarra recorre la zona, capturando y fusilando a los últimos huelguistas dispersos en la región. Hacia mediados de diciembre, Varela se traslada a la zona norte de Santa Cruz, arribando a Puerto Deseado el día 18 de diciembre con el objetivo de terminar la huelga en esta zona. Mientras, a fines de noviembre el Capitán Anaya parte de Puerto Santa Cruz hacia el noroeste en busca de los huelguistas que operaban en el norte del territorio. Atrapa a un grupo numeroso en la zona de Cañadón León (donde hoy en día se halla la localidad de Gobernador Gregores) y fusila un gran número de huelguistas. Posteriormente continúa la persecución hacia el noreste, donde realiza dos capturas masivas en las zonas de las estancias San José y Tres Cerros y fusila un gran número de huelguistas en cada una de ellas, la última de estas a fines de diciembre. Otro grupo, comandado por Facón Grande, se desprende de estos grupos perseguidos por el Capitán Anaya y comienza a operar en torno a las vías del Ferrocarril Patagónico que unía los poblados de Puerto Deseado y Las Heras. En Puerto Deseado Varela tiene el objetivo de buscar y capturar a este último grupo y con ello dar por terminada la huelga en todo el territorio de Santa Cruz.

\section{Estudios previos}

Los estudios de las huelgas de peones rurales en Santa Cruz entre los años 1921 y 1922 son iniciados de manera sistemática por Osvaldo Bayer en dos artículos publicados en la revista Todo es Historia (Bayer, 1968a, 1968b) que luego ampliaría y compilaría hasta editar los cuatro tomos que componen la obra Los Vengadores de la Patagonia Trágica (Bayer, 1972a, 1972b, 1974 y 1984). Hasta ese momento, esta temática había sido escasamente encarada por la historia y solo se habían publicado algunos análisis y estudios, principalmente en el marco de investigadores militares o afines, quienes discutían las motivaciones e intereses detrás de la huelga (Bohoslavsky, 2005). Estudios más recientes se han orientado a investigar los contextos sociales y económicos de la huelga, o su influencia posterior en varios aspectos de la sociedad santacruceña y nacional (por ejemplo Ferrante, 2009).

En cuanto a la generación de cartografías o representaciones en mapas de la huelga de 1921, los antecedentes son muy escasos. En este sentido, en la edición de 1994 del Tomo II de La Patagonia Rebelde se suma un mapa - que no estaba en las ediciones anteriores - con los centros poblados y estancias más relevantes vinculadas con la huelga, así como también, se remarcan las áreas de operaciones de los distintos jefes militares (Bayer, 1994). Además, se han realizado mapas por historiadores amateurs de la zona (Reinoso, 1999), aunque en este último caso incluyen numerosos errores. La reconstrucción más minuciosa es la llevada a cabo por Melo (2014) en todo el territorio de Santa Cruz, en la cual, a partir de la obra de Bayer junto con otra bibliografía histórica, realiza una reconstrucción de los movimientos de los huelguistas y el Ejército. De esta forma, localiza algunos eventos específicos como rendiciones, enfrentamientos y campamentos; sin embargo, este recorrido presenta algunos errores en la ubicación de ciertos establecimientos ganaderos y recorridos realizados.

\section{Construcción del SIG Patagonia Rebelde}

Para avanzar en la resolución de los objetivos planteados al inicio, se decidió crear un Sistema de Información Geográfico (SIG) y una base de datos documental sobre los 
sucesos ocurridos en el área de estudio (Zubimendi et al., 2014, Zubimendi et al., en prensa). De esta forma, seguimos dos enfoques complementarios, paralelos y continuos que nos permitieron: por un lado, crear una base de datos geográfica para ubicar espacial y temporalmente cada suceso y, por otro, construir cartografías temáticas que pudieran aportar una visión gráfica de la huelga. A su vez, se trabajó en dos escalas espaciales: una escala menor y de baja resolución específica, que posibilitará organizar los lugares donde ocurrieron los eventos y crear una secuencia espacial de los mismos, y una escala mayor para aquellos casos de interés especial que requieren una mayor precisión en las fuentes utilizadas y que pudieran ser útiles para identificar lugares específicos, tales como entierros, fosas comunes o campamentos (ver Zubimendi, Sampaoli, Reynoso y Tagliorette, 2017). Para lograr esto, el trabajo se organizó en una serie de etapas que se realizaron en paralelo (Figura 1), ya que cada avance en una podía proveer información útil a la otra, retroalimentándose ambas instancias: el SIG y la base de datos documental. Este es un proceso que permite la incorporación de nuevos datos continuamente, por lo que se considera a lo realizado hasta el momento como preliminar y en continuo crecimiento.

\section{Digitalización y georreferenciación de mapas}

A fin de construir el SIG Patagonia Rebelde se digitalizaron mapas y planos de estancias para obtener imágenes raster de distintos momentos a lo largo del siglo XX y comienzos del XXI correspondientes a las estancias, localidades y otros elementos espaciales en que se ordena el territorio (Tabla 1). Estas imágenes raster fueron georreferenciadas y guardadas como imágenes GeoTIFF. Como paso posterior se generaron capas vectoriales de polígonos en formato shapefile para cada uno de los mapas y planos digitalizados. Se empleó el sistema de coordenadas geográficas GCS_WGS_1984 y el datum D_WGS_1984. El recorte geográfico del área de estudio abarca el noreste del territorio de Santa Cruz, desde el paralelo $49^{\circ} \mathrm{S}$ hacia el Norte, hasta el límite con la provincia de Chubut; y desde el meridiano $70^{\circ} \mathrm{O}$ hacia el Este hasta la costa del océano Atlántico. Para concretar estos dos pasos se utilizaron software específicos, inicialmente QGIS 2.4 y luego ArcGIS 10.2. Dentro de estas capas, cada polígono correspondía a diferentes elementos identificados en las imágenes raster. Estos polígonos fueron clasificados en distintos tipos de acuerdo a sus características: a) estancias; b) localidades y pueblos; y c) otros en el caso de que los hubiera (por ejemplo, estaciones de ferrocarril, tierras fiscales, reservas indígenas, reservas de tránsito y Parques Nacionales). Otros datos vectoriales empleados, como por ejemplo, los límites departamentales de la Argentina y líneas de ferrocarril, fueron obtenidos del Instituto Geográfico Nacional (IGN). Los mismos corresponden al SIG250 de dicha institución, con una escala de 1:250.000, cuyas capas fueron transformadas al sistema de coordenadas geográficas y datum mencionados arriba. De esta forma se conformó un Sistema de Información Geográfica que abarca todo el noreste de Santa Cruz; así como distintos momentos temporales de acuerdo a las fuentes disponibles y consultadas. Las unidades mínimas de análisis espacial consideradas son los polígonos, que en la gran mayoría de los casos corresponden a establecimientos dedicados a la ganadería ovina.

Un problema importante que surgió en relación a la determinación de los lugares que corresponden a sucesos de la huelga son las múltiples denominaciones otorgadas a los establecimientos ganaderos a lo largo de los años. En este sentido, las estancias podían ser conocidas por su nombre comercial (como lo es actualmente en todos los mapas de estancias), o también por el nombre de su dueño, alguno de los socios dueños, o incluso el del administrador. Es por ello que paralelamente a la construcción de las distintas capas del SIG se procedió a realizar una exhaustiva reconstrucción de la historia y cambios de los establecimientos ganaderos; y en especial una reconstrucción de quiénes eran los dueños de los mismos en el año 1921. Para este fin se emplearon los propios mapas y planos, así como principalmente los relatos de los sucesos de la huelga de 

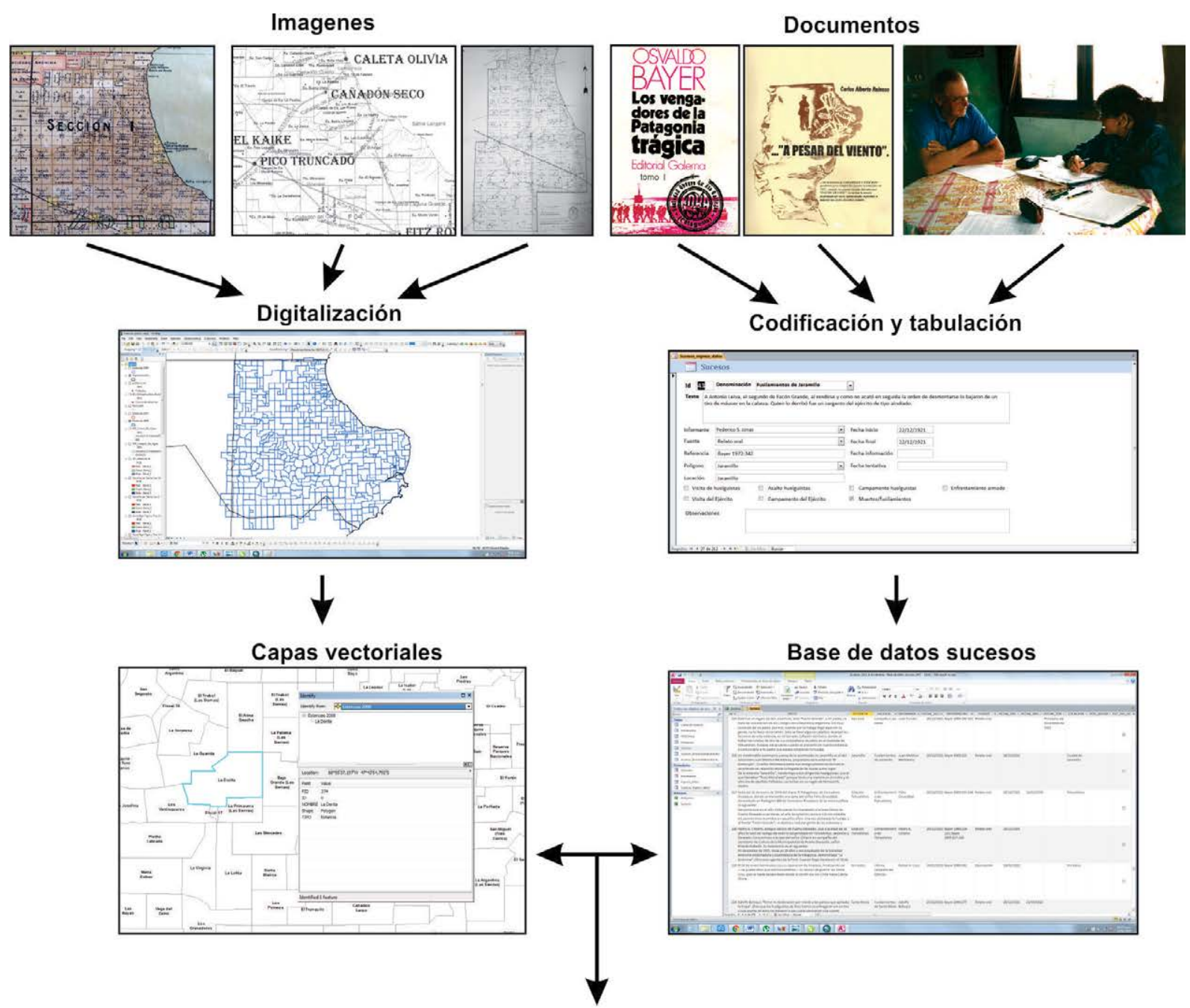

\section{SIG Patagonia Rebelde}

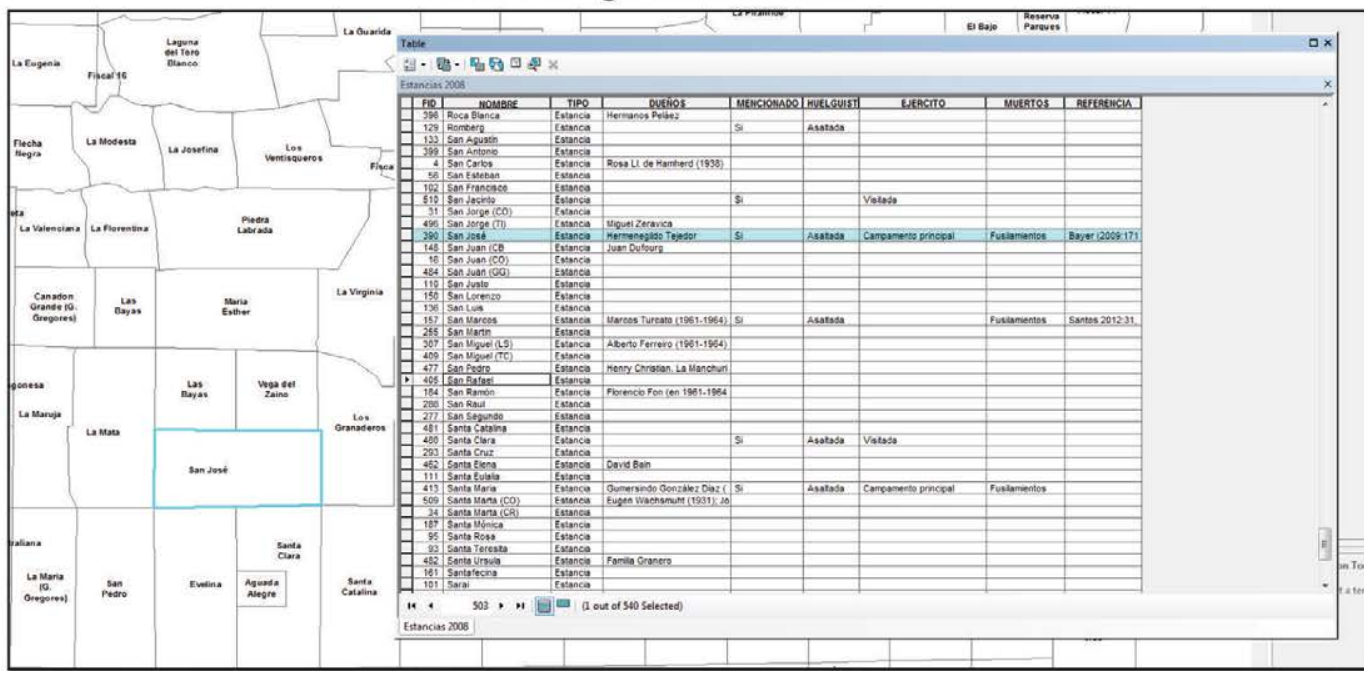

Figura 1. Esquema de la metodología seguida en las investigaciones sobre la segunda huelga de peones rurales durante el año 1921. 


\begin{tabular}{|c|c|c|c|}
\hline $\mathbf{N}^{\circ}$ & Año & Descripción & Territorio \\
\hline 1 & 1903 & $\begin{array}{l}\text { Plano de la Gobernación de Santa Cruz y Territorio de Magallanes. } \\
\text { Wilkinson y Lefrançois (escala 1:666.666) }\end{array}$ & Provincia de Santa Cruz \\
\hline 2 & 1923 & Plano del Territorio de Santa Cruz. von Sterneck (escala 1:666.666) & Provincia de Santa Cruz \\
\hline 3 & 1927 & $\begin{array}{l}\text { Plano del Territorio Nacional de Lafrancoise, Porri y Fernández Rive- } \\
\text { ra (escala 1:800.000) }\end{array}$ & Provincia de Santa Cruz \\
\hline 4 & ca. 1930 & Mapa de Jurisdicción de Subcomisaría Pico Truncado (sin escala) & $\begin{array}{l}\text { Pico Truncado, Caleta Olivia, Koluel } \\
\text { Kaike, Tehuelches (y alrededores) }\end{array}$ \\
\hline 5 & 2004 & INTA EEA Santa Cruz (1:500.000) & Departamento Deseado \\
\hline
\end{tabular}

Tabla 1. Datos de los mapas y planos digitalizados.

1921 (por ejemplo, Bayer, 1972b), así como otros libros y memorias sobre las estancias patagónicas de la zona (Ciselli, 1999; Ibarroule et al., 2011) y de antiguos pobladores (por ejemplo, Santos, 2012; Tirachini, 1955, etc.) entre otras diversas fuentes. Como paso final, se confeccionó una capa vectorial en formato shapefile con información sobre el nombre de las estancias y sus dueños para el año 1921. Conviene resaltar que solo en aproximadamente la mitad de los casos se cuenta con la certeza de que eran dueños o administradores al momento de la huelga, los restantes corresponden a dueños de pocos años, antes o después. Esta capa, con su información asociada, es la que se empleó en los distintos estudios y reconstrucciones históricas de los sucesos de las huelgas de peones rurales.

\section{La base de datos documental}

Este paso consistió en una lectura pormenorizada y sistemática de la bibliografía existente con relación a la huelga de 1921, principalmente los cuatro tomos de la obra Los Vengadores de la Patagonia Trágica del historiador Osvaldo Bayer (1972a, 1972b, 1974 y 1984), así como algunas ediciones recientes en las que brinda nueva información (como Bayer, 2009). También se emplearon otras obras que describen parte de los sucesos de la huelga, como relatos de participantes directos, por ejemplo el Diario de Guerra del Ejército Argentino (1921-1922) y pobladores o peones rurales (Castagno, s/f; Tirachini, 1955). Se han incorporado a su vez, entrevistas y descripciones realizadas por historiadores amateurs de la zona (Reinoso, 1999; Santos, 2012; Suárez Samper, 2010; entre otros) quienes, impulsados por la labor realizada por Bayer, comenzaron a recuperar parte de la memoria oral y escrita de los antiguos habitantes del noreste de Santa Cruz. También se ha empleado el archivo sonoro del proyecto de investigación, en el cual se cuenta con entrevistas a antiguos pobladores y descendientes (Sampaoli e Ibarroule, 2010).

La base de datos documental se realizó con el programa Microsoft Access 2010, en la cual se fue ingresando la información. Para ello se creó una ficha donde se transcribieron fragmentos de información que pudieran ser situados espacialmente en un determinado polígono del SIG. También se registró en los casos posibles, la fecha en que ocurrió el suceso; el tipo de fuente de la información - ya sean partes del diario o telegramas del ejército, relatos orales, notas de diarios, entre otras-; el nombre del informante; así como una tabulación de la información en ciertos sucesos (por ejemplo asaltos de los huelguistas en la zona de Las Sierras, o campaña del Teniente Coronel Varela en la zona del Deseado) lo que permitió agrupar fragmentos de textos que refieren los mismos eventos; además se consignaron aquellas informaciones que referían a la muerte o fusilamiento de huelguistas, o campamentos de huelguistas o del Ejército; por último se registró la referencia bibliográfica o documental correspondiente. 


\section{Resultados obtenidos}

Con el SIG Patagonia Rebelde es posible generar cartografías temáticas y reconstrucciones históricas que aportan y complementan al conocimiento de cómo se desarrolló la huelga de peones rurales de fines de 1921 y comienzos de 1922 y constituye también una herramienta para otros estudios vinculados con otros aspectos de esta problemática.

\section{Cartografías temáticas}

En todos los sucesos registrados en la base de datos documental se hace mención a 130 polígonos distintos. Estos corresponden al 19,7\% del total de polígonos del área de estudio a comienzos de la década de $1920(\mathrm{n}=660)$. Este valor constituye un número elevado si consideramos que amplios sectores no fueron afectados directamente por la huelga, como la mayoría de los establecimientos ganaderos de la costa o cerca de Puerto Deseado, que existe todavía un número no determinado de estancias referenciadas en las fuentes documentales pero que no hemos podido establecer a qué polígono corresponde, o que aún no se han finalizado los análisis de todas las fuentes documentales disponibles en el equipo. Todo esto hace que el número real de establecimientos ganaderos que se vieron afectados por la huelga posiblemente haya sido mayor al que contamos en este momento.

En la Figura 2 se representan todos los lugares mencionados en la base de datos hasta este momento junto con otros elementos del mapa, tales como poblaciones y el Ferrocarril Patagónico, que permiten ubicar espacialmente la huelga de 1921. En este sentido, si bien el movimiento obrero tuvo su origen en las localidades ubicadas en la costa, como Río Gallegos, Puerto San Julián y Puerto Santa Cruz, en el caso de la zona norte, la huelga tuvo escasa presencia en Puerto Deseado y los restantes asentamientos ubicados en la costa: Bahía Laura, Cabo Blanco, Mazarredo y Caleta Olivia. Sólo esta última se vio afectada por la huelga, cuando el día 17 de diciembre son asaltadas varias casas de comercio. De acuerdo con los polígonos mencionados en la base documental (Figura 2), podemos observar que la huelga en términos generales - o sea, el accionar de los huelguistas y del Ejército Argentino en su persecución - se concentró principalmente en la parte central del territorio analizado, zona conocida comúnmente como Las Sierras y que corresponde al Nesocratón del Deseado, donde se hallaba el límite del avance ganadero para comienzos de la década de 1920, proceso que aún se hallaba inconcluso al momento de la huelga (Barbería, 2001; Ciselli, 1999). Las fuentes sobre la huelga en esta zona del territorio son muy abundantes y diversas, ya que existe información brindada por el Ejército Argentino, pobladores y huelguistas, entre otras. Algo similar ocurre a torno a las poblaciones y establecimientos cercanos al Ferrocarril Patagónico, sobre todo entre la estación Tehuelches y Las Heras. También se destacan las menciones en cercanías de Caleta Olivia, aunque en este último caso, estas son brindadas casi únicamente por una única fuente documental (el manuscrito inédito de un peón rehén de los huelguistas), ya que prácticamente no existen referencias al accionar de los huelguistas en torno a esta localidad.

Por su parte, también se puede analizar la cantidad de polígonos —en su inmensa mayoría estancias- mencionados por algunas de las fuentes documentales que se han empleado. Por ejemplo, Bayer utiliza diversas fuentes en su obra (cuatro tomos y un volumen que resume a los anteriores), entre las que se destacan abundantes entrevistas a personas que vivieron los hechos y realiza una detallada reconstrucción de los sucesos de la huelga de 1921 (Figura 3A). En toda su obra hace mención a 44 lugares (el 33,8\% de los de la base de datos documental), los cuales abarcan toda al área afectada por la huelga. Por su parte, en el "Diario de guerra Regimiento $N^{\circ} 10$ de Caballería "Húsares de Pueyrredón”, Campaña de Santa Cruz, Resumen General, Año 1921/22” documento inédito que consta de 166 folios, se hace mención a 55 polígonos $(42,5 \%)$ casi todos 


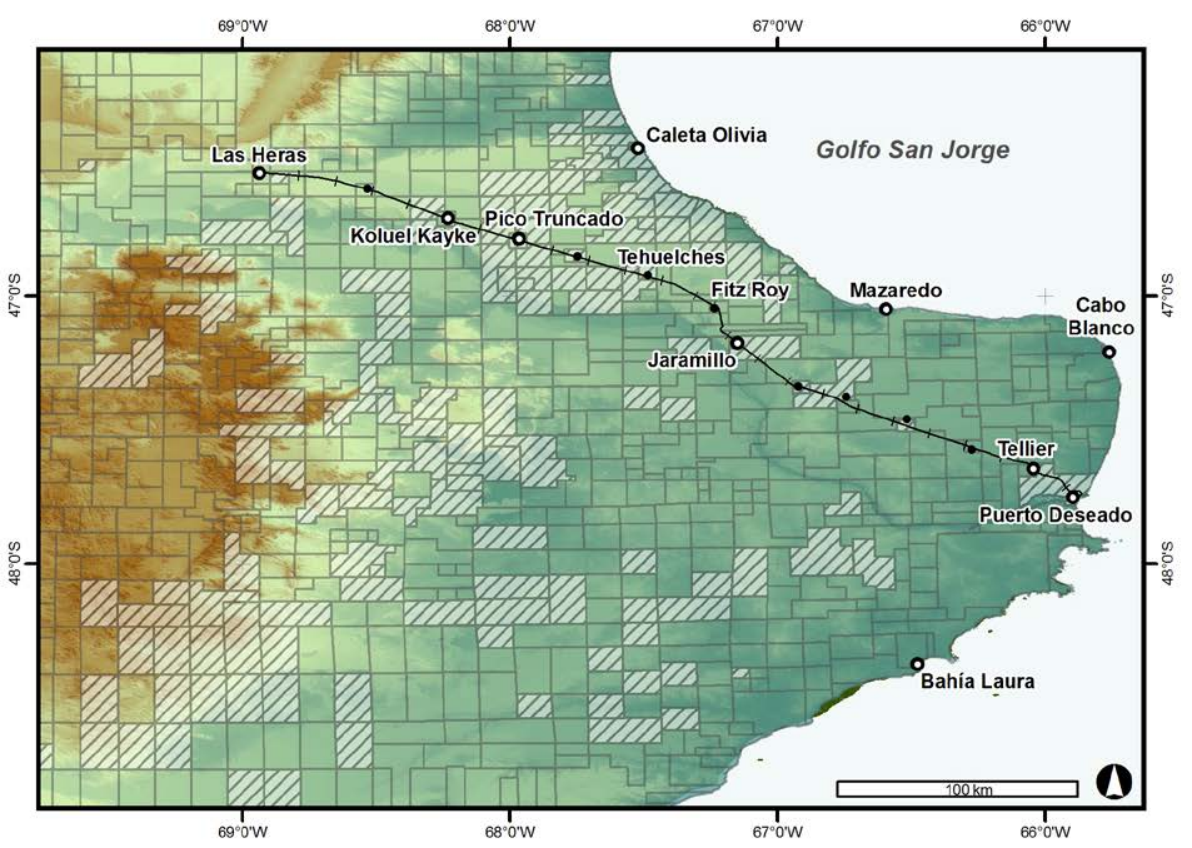

\section{Sig Patagonia Rebelde}

Polígonos mencionados en la base de datos documental

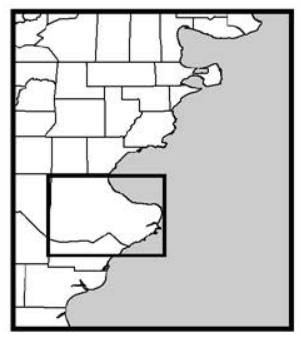

Referencias

- Poblaciones

- Estaciones del Ferrocarril Ferrocarril Patagónico Mencionados No mencionados

Figura 2. Polígonos mencionados en la base de datos documental registrados hasta septiembre de 2017 junto con otras referencias del territorio.

2. Manuscrito inédito del cual existe una copia en poder del equipo de investigación. El mismo ha sido utilizado también de forma parcial por algunos historiadores amateurs de la zona (entre otros,

Santos, 2012 y Maggiori, 2012). ellos de la zona sur (Figura 3B). Otra fuente documental es el manuscrito realizado por un peón rural llamado José "Pepe" Castagno² (s/f), quien relata con gran detalle los sucesos que le tocaron vivir durante la huelga, en la cual asegura que fue rehén de los huelguistas. Este manuscrito constituye un relato único e invaluable para conocer de primera mano los movimientos y acciones llevadas a cabo por un grupo de huelguistas en el noreste de Santa Cruz, en especial, con relación a los movimientos del grupo y los lugares por donde pasaron (Zubimendi, Sampaoli y Reynoso, 2015). Si bien menciona una cantidad relativamente baja de lugares $(n=24 ; 18,4 \%)$, constituye casi la única fuente sobre el accionar de los huelguistas en los alrededores de Caleta Olivia (Figura $3 \mathrm{C}$ ), por lo que aporta información sobre una zona que, como ya dijimos, cuenta con pocos antecedentes.

Por último, en la Figura 3D se presentan 24 polígonos en los que existen referencias a muertes o fusilamientos vinculados con la huelga entre diciembre de 1921 y enero de 1922, mientras que en la Tabla 2 se presentan algunos datos contextuales sobre los mismos. Es necesario destacar que si bien la gran mayoría de los muertos fueron huelguistas o personas sospechadas de serlo, también fallecieron otras personas en sucesos directamente vinculados con la huelga: el conscripto Domingo Montenegro quien murió por el disparo de un compañero de armas en la estancia Santa María (Ejército Argentino, 1921-1922, folio 88); Pablo Fisher, otro conscripto, en Puerto Deseado como consecuencia de las heridas recibidas en el combate de Tehuelches (Ejército Argentino, 1921-1922, folio 39); así como también el estanciero noruego Juan Flekke o Flekker quien falleció en su estancia Bella Vista en circunstancias dudosas (Bayer, 1984, pp. 131-133). Sin duda, el total de localizaciones en los que existen menciones a muertes representa un número alto sobre el total de referencias, en especial si consideramos que corresponde al 18,4\% del total de polígonos mencionados en la base de datos documental y la muerte de un mínimo conservador de más de 50 personas en total. A su vez, existen casos en que no está claro donde ocurrió un suceso, como tres huelguistas que estaban prisioneros en Puerto Deseado sobre los cuales se ha mencionado que fueron fusilados tanto en Puerto Deseado como en Puerto Jenkins, 

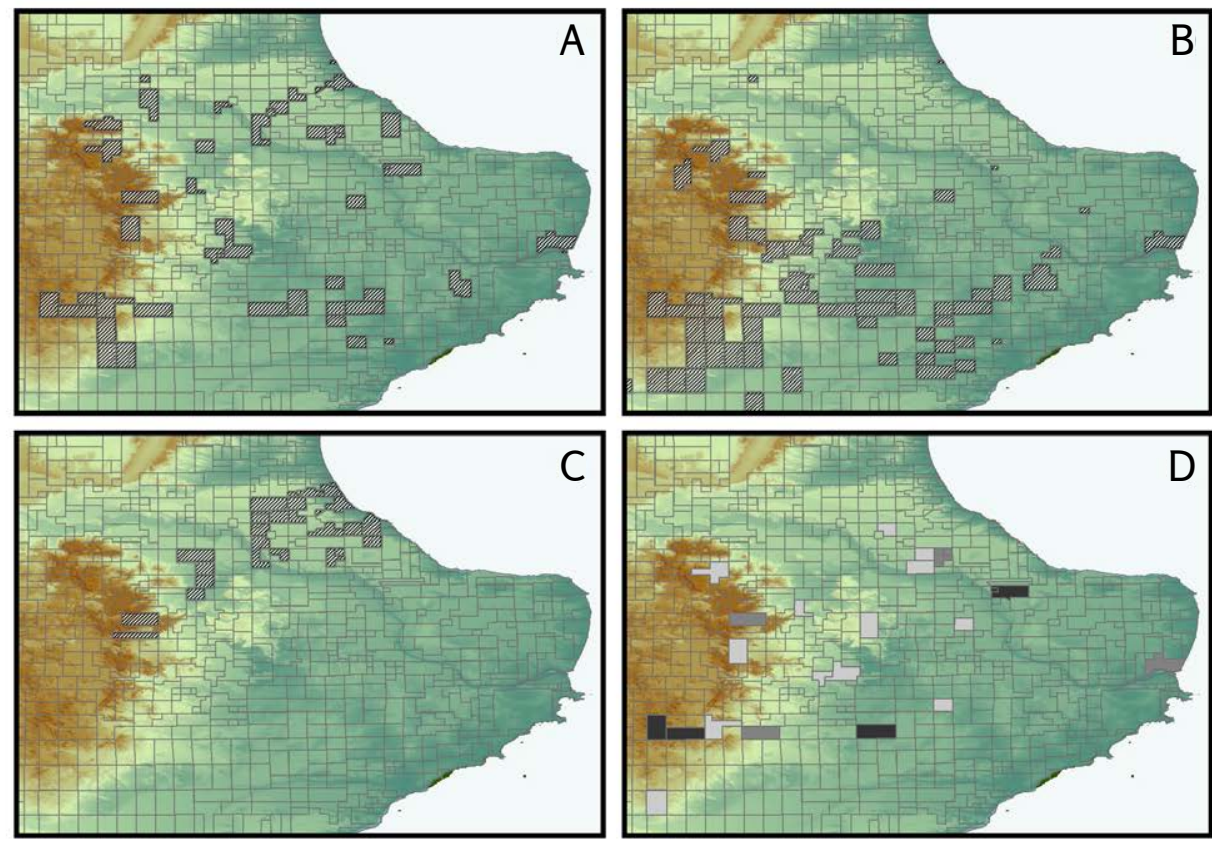

\section{Sig Patagonia Rebelde}

Polígonos mencionados según fuentes documentales y polígonos con referencias a muertes o fusilamientos

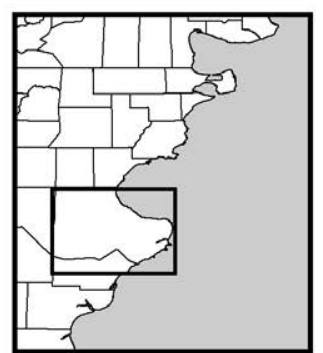

Referencias

Mencionado

1 muerto

Entre 2 y 10 muertos

Más de 10 muertos

Figura 3. Cartografías temáticas realizadas a partir de la base de datos documental. A) Polígonos mencionados en los libros de O. Bayer (1972b, 1974, 1984, 2009); B) Polígonos mencionados en el Diario de Guerra (Ejército Argentino, 1921-1922); C) Polígonos mencionados en el manuscrito de José Castagno (s/f); D) Polígonos en los que se han mencionados muertos o fusilamientos de peones rurales entre fines de 1921 y principios de 1922 (ver Tabla 2).

sobre la margen sur de la ría y frente a dicha localidad (Bayer, 1972b, p. 329, 1984, pp. 205-207, 2009, pp. 220, 222).

\section{Reconstrucción de movimientos de tropas del Ejército}

El SIG Patagonia Rebelde también se puede utilizar para generar reconstrucciones del movimiento de ciertas personas o grupos por el territorio, al menos a una escala espacial amplia o de grano grueso. Dado que la base de datos documental cuenta con la información sobre la ubicación y momento de cada suceso, es posible generar secuencias espaciales y temporales de los mismos. A pesar de que parte de la información es fragmentaria, contradictoria o incompleta, en algunos casos es posible realizar este tipo de reconstrucciones. A su vez, se pueden emplear distintas fuentes para controlar la verosimilitud de las mismas. En un trabajo previo se realizó una reconstrucción del recorrido de José Castagno y una partida de huelguistas por el noreste de Santa Cruz, incluyendo el asalto a dos casas comerciales del pequeño poblado de Caleta Olivia y su huida del campamento del Cañadón del Carro luego del combate de Tehuelches (Zubimendi et al., 2015). En esta oportunidad y como ejemplo de la aplicación del SIG Patagonia Rebelde, presentamos la reconstrucción de los movimientos de las tropas al mando del Capitán Anaya por el noreste de Santa Cruz. Para ello utilizamos los folios 115 a 166 del "Diario de guerra Regimiento No 10 de Caballería "Húsares de Pueyrredón", Campaña de Santa Cruz, Resumen General, Año 1921/22" (Ejército Argentino, 1921-1922), que corresponden a las Memorias escritas en el momento de los hechos tanto por el capitán como sus subalternos el Teniente Correa Morales y los Subtenientes Sidders y Loza.

\section{6 al 20 de diciembre de 1921 (Figura 4)}

Las acciones se inician luego de la captura de un grupo numeroso de huelguistas en Cañadón León, cuando el Capitán Anaya se entera de que otro grupo, comandado 


\begin{tabular}{|c|c|c|c|}
\hline Polígono & Fecha & Muertos & Observación \\
\hline La Alianza & $5 / 12 / 1921$ & 1 & Muerto en enfrentamiento \\
\hline La Linda & $s / f$ & 1 & Sin datos \\
\hline Tres Lagunas & $s / f$ & 1 & Sin datos \\
\hline 9 de Septiembre & $21 / 12 / 1921$ & 1 & Falleció por heridas del combate de Tehuelches \\
\hline Friedrichstadt & $s / f$ & 1 & Sin datos \\
\hline Sierras Blancas & $s / f$ & 1 & Sin datos \\
\hline Ea. Jaramillo & $20 / 12 / 1921$ & 3 & Muertos en enfrentamiento \\
\hline El Alma Gaucha & $31 / 12 / 1921$ & 1 & Asesinado, previamente torturado \\
\hline Cerro Horqueta & $s / f$ & 1 & Sin datos \\
\hline Bella Vista & $\sim 9 / 12 / 1921$ & 1 & Estanciero, muerto por los huelguistas o accidental \\
\hline $\begin{array}{l}\text { La Sin Nombre/ Santa María/ } \\
\text { Tres Cerros/ La Aida }\end{array}$ & 25 y $28 / 12 / 1921$ & Más de 10 & $\begin{array}{l}\text { Fusilamientos masivos de huelguistas prisioneros. Un } \\
\text { conscripto muerto por disparo accidental }\end{array}$ \\
\hline Los Granaderos & $16 / 12 / 1921$ & 1 & Fusilamientos de huelguista prisionero \\
\hline Tehuelches/San Marcos & $21 / 12 / 1921$ & 2 & Fallecidos por heridas del combate de Tehuelches \\
\hline Manantiales & $2 / 1 / 1922$ & 4 & Fusilamientos de huelguistas prisioneros \\
\hline Puerto Deseado & $22 / 12 / 1921$ & 1 & Conscripto muerto por heridas del combate de Tehuelches \\
\hline Puerto Deseado/ Puerto Jenkins & $25 / 12 / 1921$ & 3 & Fusilamientos de huelguistas prisioneros \\
\hline El Moscoso & 22 y $23 / 12 / 1921$ & Más de 10 & Fusilamientos masivos de huelguistas prisioneros \\
\hline Jaramillo & 22 y $23 / 12 / 1921$ & 10 & Fusilamientos de huelguistas prisioneros \\
\hline San José & $18 \mathrm{al} 21 / 12 / 1921$ & Más de 10 & Fusilamientos masivos de peones prisioneros \\
\hline La Mata & $17 / 12 / 1921$ & 3 & Fusilamientos de huelguistas prisioneros \\
\hline
\end{tabular}

Tabla 2. Datos sobre polígonos en los que existen referencias a muertes vinculadas con la huelga en el noreste de Santa Cruz entre diciembre de 1921 y enero de 1922. Datos tomados de: Bayer 1972b, 1984, 2009; Ejército Argentino, 1921-1922; Reinoso 1999 y Santos, 2012.

3. Bayer publicó el relato de Vicente Juanes, el cabecilla de la partida de huelguistas que se enfrentó en dos oportunidades al Subteniente Sidders en la estancia La Alianza. En este relato manuscrito, Juanes brinda el nombre de los 10 integrantes de la partida, afirma que el primer enfrentamiento no fue tal, sino que se fusiló a tres huelguistas; mientras que en el segundo encuentro un huelguista falleció al enfrentarse con dos soldados y otros dos fueron fusilados (Bayer, 1984, pp. 256-261). De esta forma, el número de muertos pasa de dos según afirma Sidders, a seis según el relato de Vicente Juanes. por Albino Argüelles, se hallaba al noreste y operaba de forma independiente del grupo ubicado al sur del río Chico que acababa de disolver. Es por ello que comienza la búsqueda de este dirigente de la huelga. El día 5 de diciembre de 1921 envía al Subteniente F. Sidders hacia la estancia La Alianza, cercana a Bajo del Tigre, donde les proveerían de caballos para corroborar esta información. Ese mismo día, en cercanías de La Alianza, el Subteniente Sidders afirma que tuvo dos enfrentamientos con 15 huelguistas, matando a dos de ellos y tomando dos prisioneros ${ }^{3}$ y reafirma las noticias de un campamento de cerca de 300 personas en Bajo del Tigre. El 7 de diciembre Anaya se traslada junto con toda su tropa, pasando por la estancia La Alianza y llegando al anochecer a la estancia Río Seco de A. Feu. En este establecimiento capturan al socio del dueño por proteger a un huelguista que había resultado herido de bala en la refriega del 5 de diciembre cerca de La Alianza. Continúan hacia Bajo El Tigre, donde encuentran restos del campamento de los huelguistas, el cual habría sido abandonado poco tiempo antes. Luego de descansar exploran el puesto de J. Fernández que hayan abandonado y luego se dirigen a El 18 de M. Gensana. Al día siguiente, 9 de diciembre, recorre el territorio, volviendo a la estancia La Alianza desde donde envía una partida al mando del Subteniente Sidders a la estancia de los hermanos Gastaldi para obtener información sobre el paradero de los huelguistas. Anaya recibe noticias de que dos huelguistas fugados se hallaban en la zona de la estancia Río Seco, por lo que envía otra patrulla a cargo del Sargento Espínola a dicha estancia. El día 10 a la noche regresa el 
Subteniente Sidders con noticias de que las estancias de los hermanos Gastaldi y Los Molinos no habían sido afectadas por la huelga. Al día 11 se da descanso a la tropa y a la caballada, cansada por los reconocimientos realizados los días previos. A su vez, regresa el Sargento Espínola, trayendo tres detenidos e informando que los huelguistas habían trasladado su campamento a las inmediaciones del Cerro El Mirador en la estancia Santa Catalina. El día 12 Anaya recibe más noticias referidas al campamento de El Mirador, donde le informan que habría 200 hombres, por lo que decide enviar al Teniente Correa Morales hacia el mismo, con órdenes luego de reunirse con él en la estancia Vega Grande. Al día siguiente, Anaya parte hacia Vega Grande, pasando antes por las estancias El 18 y Río Seco, donde hace noche debido a un temporal de viento. El 14 se reúnen ambos grupos del Ejército y el Teniente Correa Morales le informa que los huelguistas habían asaltado varias estancias en la zona, llevándose abundante provisión de víveres y caballos, reuniéndose efectivamente en Cerro Mirador, pero que no pudo ir al mismo por la peligrosidad del terreno y por tener los caballos agotados. Ese mismo día Anaya envía al Sargento Arriola a comprobar si los huelguistas aún se hallaban en el cerro Mirador, regresando al poco tiempo para comprobar que ya no se encontraban allí. Luego, manda al Cabo $1^{\circ}$ Landa a buscar a Ramiro Álvarez, poblador cercano, el cual tendría en su poder un pliego de condiciones entregado por los huelguistas; regresando a las pocas horas, de madrugada, con dicho poblador quien desconoce toda referencia al respecto.

Al amanecer del día 15 parte hacia Aguada Alegre el Subteniente Sidders como punta de lanza del escuadrón. Durante la marcha, observa un comportamiento sospechoso del administrador de dicho establecimiento, por lo que lo toma prisionero. A su vez, Anaya luego de llegar a Aguada Alegre, toma conocimiento de que Martense, un español que tenía un boliche de campo en las cercanías, había actuado de enlace con el campamento de los huelguistas. Es por ello que Anaya decide partir hacia la estancia Los Granaderos de J. Tirachini, que se hallaba a sólo $5 \mathrm{~km}$ del boliche de Martense y podría proveer de buen alojamiento a la tropa. Así llega a dicho establecimiento y luego parte a buscar a Martense, tomándolo prisionero. Por otras noticias recibidas, Anaya se entera de que los huelguistas se hallan al Oeste, en campos de la estancia San José de S. García. Parte el día 16 con el escuadrón hacia la misma, bajo una intensa granizada, llegando ese mismo día. El administrador de San José le informa a Anaya de que aproximadamente 300 huelguistas junto con 1.500 caballos estaban dirigiéndose hacia el Oeste. Al mismo tiempo, Anaya envía al Cabo $1^{\circ}$ Boccaloni hacia Vega del Zaino, quien no informa novedades y se reúne con él en San José. Al día siguiente, 17 de diciembre, Anaya sigue su marcha hacia el Oeste, hacia la zona denominada Tapera Casterán de la estancia La Mata. En el camino se topan con caballada dispersa y luego con un campamento de huelguistas. Anaya describe que en ese momento se produjo un enfrentamiento ${ }^{4}$ con los huelguistas que se extendió por una hora. Finalmente, estos se rinden, capturando casi 200 huelguistas y aproximadamente 2.000 caballos y mulas, que son conducidos hacia la estancia San José. Allí se liberaron varios rehenes, casi todos ellos dueños de establecimientos ganaderos de la zona.

\section{0 al 29 de diciembre de 1921 (Figura 5)}

Anaya permanece en la estancia San José decidiendo el destino de los prisioneros y devolviendo caballada a los dueños de las estancias cercanas hasta el día 20 de diciembre. Ese día se pone en marcha hacia la estancia La Aida del ex-comisario Albornoz, ubicada al este de San José, en busca de otro grupo de huelguistas. Cuando llega, al día siguiente envía una patrulla con el Teniente Correa Morales a recorrer un amplio territorio al sureste de La Aida, pasando por varias estancias, como Santa María de M. Martinovich, Laguna Chica de la sucesión de A. Aguirre y Florida Negra de G. Hope, entre otras. Esta patrulla regresa el día 22 informando que todas estas estancias habían sido asaltadas
4. A pesar de que el Capitán Anaya describe lo ocurrido en Tapera Casterán como un enfrentamiento, Bayer discute ampliamente esto, demostrando que allí lo que ocurrió en realidad fue el fusilamiento de los cabecillas, ya que los muertos corresponden a los líderes del grupo: Albino Arguelles, otro conocido como Jara "Tres Dedos" o "El Paraguayo" y un tercero de apellido Ledesma. Por su parte, no se produjeron muertos ni heridos entre la tropa del Ejército Argentino (Bayer, 1972b, 1984). 


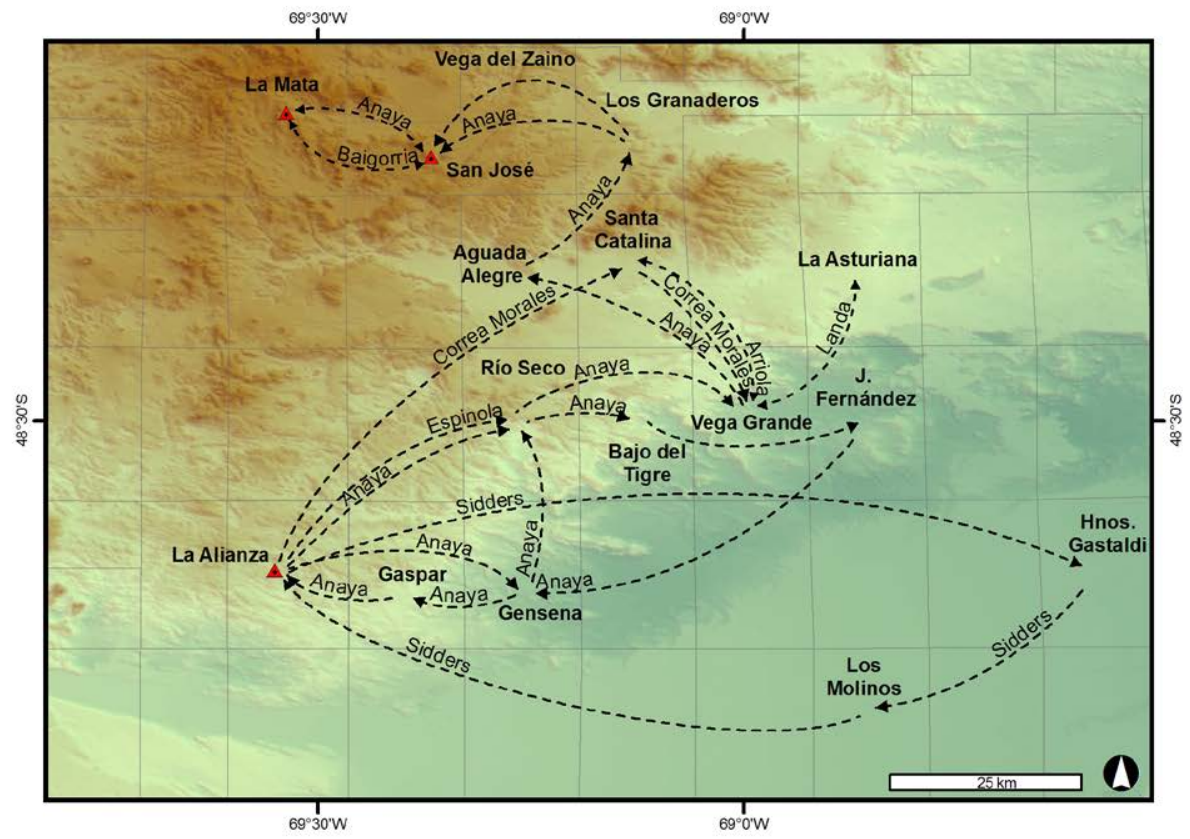

Sig Patagonia Rebelde

Movimientos del escuadrón a cargo del Capitán Anaya ( 6 al 20 de diciembre de 1921)

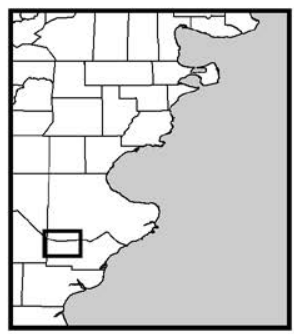

Referencias

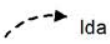

$\longrightarrow$ Ida y vuelta

A Muerte/fusilamiento

Figura 4. Movimientos del Capitán Anaya y las tropas a su mando en la zona suroeste del Departamento Deseado entre los días 6 y 20 de diciembre de 1921.

5. Para esta fecha, ya había ocurrido el combate de Tehuelches (20 de diciembre), la rendición de Facón Grande y su gente ante Varela en Jaramillo (22 de diciembre) y el fusilamiento de este dirigente huelguistas, junto con un número no determinado de personas, en

las cercanías de Jaramillo.

6. De acuerdo con el informe del Capitán Anaya su muerte se produjo como consecuencia de un disparo accidental ocurrido por la caída del revólver del soldado Eusebio Peralta. Sin embargo, Bayer plantea la posibilidad de que haya sido el resultado de un conflicto dentro de la tropa, ya que Montenegro solía molestar a

Peralta, quien finalmente se cansó de la situación y lo mató (Bayer, 1972b, pp. 245-246).

7. Este hecho es discutido por Bayer, para quien se trató directamente de fusilamientos, empleando la referencia a la ley de fugas como una justificación para matar a los huelguistas (Bayer, 1972b, p. 239, 1984, p. 101, 2009, pp. 175-177). Entre los muertos se hallaba el bolichero de origen español Martense nombrado previamente. por los huelguistas y que un grupo numeroso se hallaba en la zona de Tres Cerros. Ante esta novedad, el día 23 de diciembre Anaya se pone en marcha en dirección al Este hacia la estancia Santa María, sin embargo, cuando está recorriendo el paraje Cerro Quemado de la estancia Piedra Negra de J. Suarez, recibe un chasque que le informa que debe partir a San Julián a comunicarse telegráficamente con el Teniente Coronel Varela quien ya se encontraba en Puerto Deseado ${ }^{5}$, por lo que deja al escuadrón a cargo del Teniente Correa Morales, con órdenes de continuar hasta Santa María. Ya en dicha estancia, Correa Morales envía dos patrullas, una a cargo del Cabo $1^{\circ}$ Gutiérrez a la estancia Laguna Chica y otra al lote 17 de E. Martinovich a cargo del Cabo $1^{\circ}$ Olivares; ambas regresan al poco tiempo sin novedades. A la noche el Capitán Anaya vuelve de San Julián. Durante su ausencia ocurre el fallecimiento del conscripto Domingo Montenegro en circunstancias poco claras ${ }^{6}$.

El 24 de diciembre, Anaya envía una patrulla dirigida por el Sargento Baigorria, junto con el ex-comisario Albornoz y otro poblador de la zona, para localizar a los huelguistas de Tres Cerros. Esta patrulla ubica un campamento de aproximadamente 150 huelguistas cerca de la estancia Tres Cerros, los mismos se hallaban prestos a abandonar el lugar pero son capturados por la patrulla del Ejército mediante un engaño, ya que los convencen que se hallaban rodeados por tropas del Ejército aunque en realidad sólo se hallaban ellos tres. De esta forma, son tomados prisioneros y trasladados hasta la estancia Santa María. Este mismo día, regresa de la estancia San José el Subteniente Sidders junto con algunos soldados, informando a Anaya de la muerte de entre cinco y diez prisioneros en un presunto intento de fuga ${ }^{7}$. Los siguientes días son empleados por el Capitán Anaya para registrar e identificar a los prisioneros, para liberar a aquellos peones que fueron recomendados por los estancieros de la zona, así como a devolver la caballada. Si bien Anaya no menciona la muerte de huelguistas, existen abundantes referencias a que ocurrieron fusilamientos entre los días 25 y 28 de diciembre, aunque estos no ocurrieron en la estancia Santa María por expreso pedido de M. Martinovich, dueño de la misma, sino que se realizan en otro lugar. Una referencia afirma que los prisioneros fueron fusilados en la estancia La Aida del ex-comisario Albornoz; a su vez, 


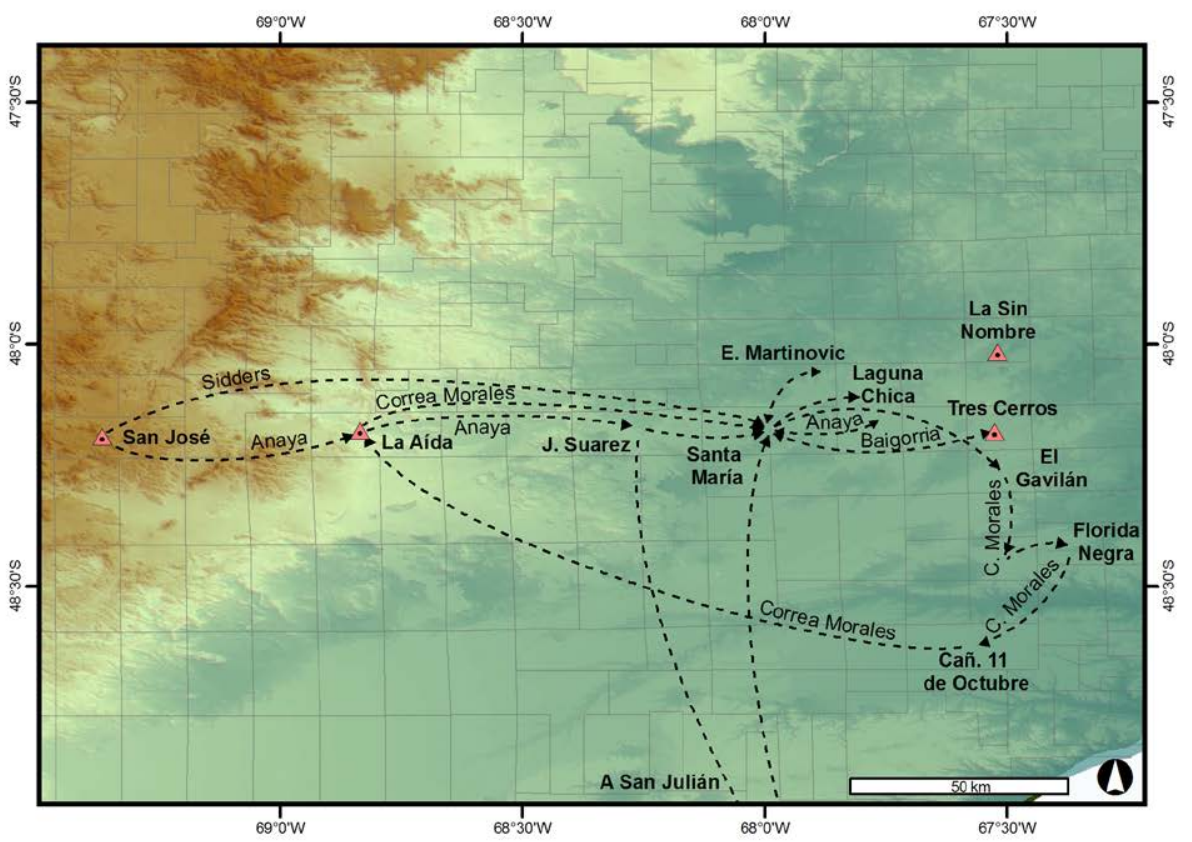

Sig Patagonia Rebelde

Movimientos del escuadrón a cargo del Capitán Anaya (20 al 29 de diciembre)

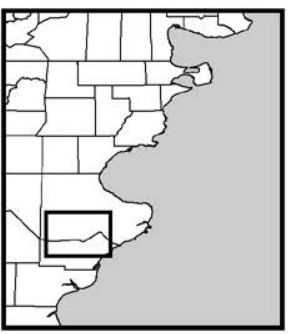

Referencias

¿ Muertes/fusilamientos

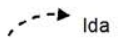

$\ldots$ Ida y vuelta

Figura 5. Movimientos del Capitán Anaya y las tropas a su mando en la zona de Tres Cerros entre los días 20 y 29 de diciembre de 1921.

se han descrito fosas comunes en algunas estancias cercanas a Santa María que podrían dar cuenta de los fusilados del grupo de Tres Cerros (Bayer, 1972b, p. 229, pp. 244-247, 1984, pp. 205-207). Estas muertes finalizan el día 28 de diciembre cuando llegan tropas de la Marina. De esta forma se da por concluida la huelga de peones rurales, aunque continúa la búsqueda y represión de aquellos involucrados en la misma.

\section{9 de diciembre de 1921 al 9 de enero de 1922 (Figura 6)}

Luego de terminar su accionar en la estancia Santa María y de entregar los prisioneros a las tropas de la Marina que llegaron a la misma el 28 de diciembre, Anaya decide emprender una última acción para capturar a los fugados y constatar la vuelta a la normalidad en el trabajo de las estancias. Para ello, divide sus tropas en tres columnas quienes deben recorrer el interior del territorio noreste de Santa Cruz y conectar con el Ferrocarril Patagónico.

La primera columna, a cargo del Teniente Correa Morales, parte hacia el Este pasando por las estancias Golondrina, Escobar (que no ha podido ser identificada), La Herradura, María Clotilde, terminando el 2 de enero de 1922 en la estación Antonio de Biedma. Esta columna recorre el territorio sin mayores novedades, comprueba que las estancias — salvo Golondrina- no se habían visto afectadas por la huelga y no encuentra huelguistas huidos o fugados.

La segunda columna, que estaba a cargo del Subteniente Sidders pero en la cual también marchaba el Capitán Anaya, parte en dirección Norte, pasando por la estancia San Miguel, donde le informaron que en las cercanías se hallaba escondido un huelguista fugado, al cual no pueden atrapar. Siguen por las estancias Madre e Hija y luego El Cuadro. En esta última, le informan que en la estancia La Pirámide, ubicada al Oeste, se hallaba un fugitivo que según le comentan era el asesino del estanciero noruego Juan Flekker, por lo que envía una patrulla allí al mando del sargento Acevedo, mientras él sigue hacia la estancia Aguada Grande. Dicha patrulla, luego de capturar a un francés, se une al Subteniente 


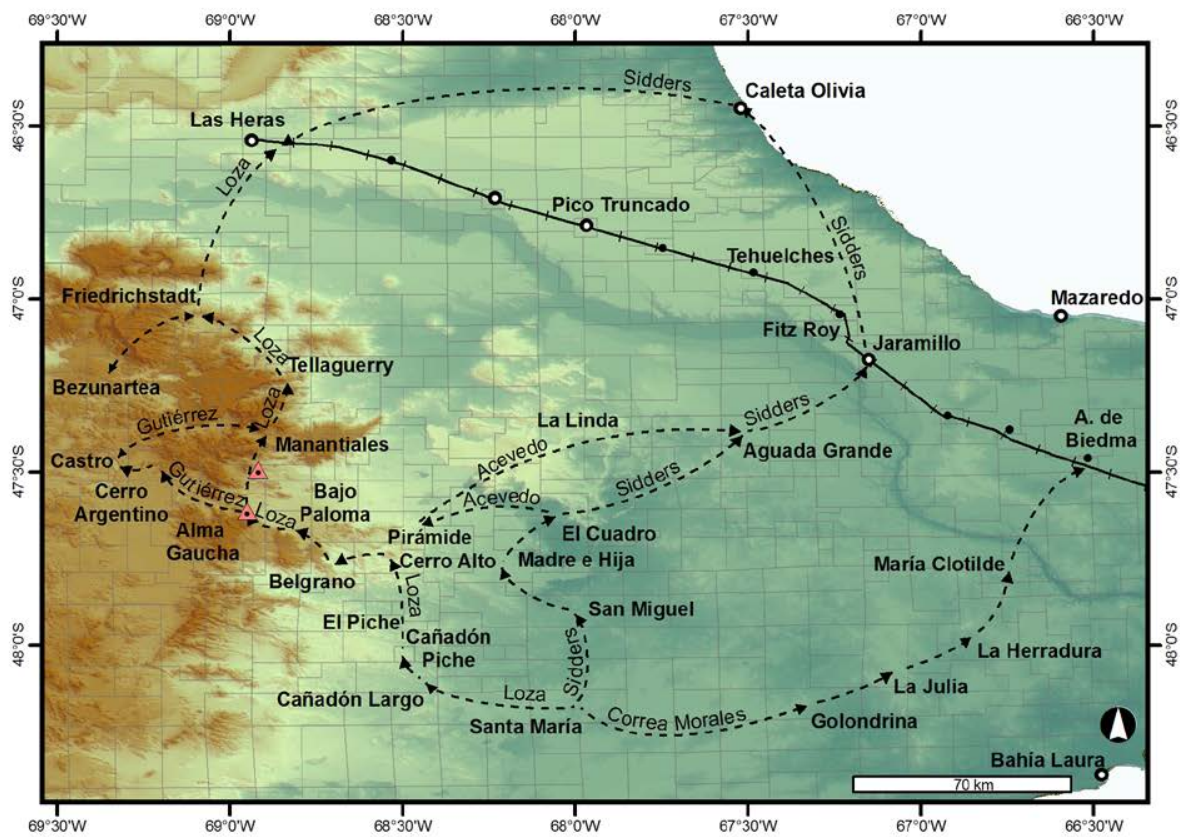

Sig Patagonia Rebelde Movimientos del escuadrón a cargo del Capitán Anaya (29 de diciembre de 1921 al 10 de enero de 1922)

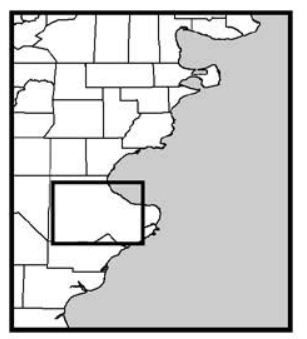

Referencias

4. Muertes/fusilamientos

$\ldots$ Ida y vuelta $\ldots \rightarrow$ Ida

Figura 6. Movimientos del Capitán Anaya y las tropas a su mando en el noreste de Santa Cruz entre los días 29 de diciembre de 1921 y 10 de enero de 1922.

Sidders y siguen rumbo a la localidad de Jaramillo. Allí se quedan un día, ya que el 7 de enero siguen hacia Caleta Olivia, aunque el Capitán Anaya se queda en Jaramillo. La patrulla llega a Caleta Olivia donde controlan el estado del pueblo, visitan algunas estancias cercanas y dos días después siguen hasta Las Heras, donde finaliza su recorrido.

La tercera columna, al mando del Subteniente Loza, parte el día 29 de diciembre en dirección Oeste, pasando por las estancias Cañadón Largo, Cañadón Piche y El Piche, donde cambian rumbo al norte y cruzan las estancias Cerro Alto, Belgrano, Bajo de la Paloma y llegan a El Alma Gaucha el 31 de diciembre. Al día siguiente, mientras están en esta estancia llega tropa de la Marina al mando del Teniente Menéndez con algunos presos que habían capturado al Norte, entre ellos Ramón Elizondo, quien es fusilado por las tropas de la Marina. El Subteniente Loza se queda durante el día en esta estancia controlando los papeles de identidad de los peones, y además encuentra ropas robadas y armas. El día 1 de enero le informan también que al Oeste podría haber fugitivos, por lo que al día siguiente envía una patrulla al mando del Cabo $1^{\circ}$ Gutiérrez con órdenes de encontrarse en la estancia Manantiales de Silvano Ruiz, hacia donde parte. El Subteniente Loza llega ese mismo día a dicha estancia a la que encuentra saqueada, en el camino tuvo un encuentro con cuatro hombres ("Gorra Colorada", Juan Campos, Juan Centeleo y el italiano Ángel Paladino) que se resistieron y fueron muertos. Se encuentra con la patrulla al mando del Cabo $1^{\circ}$ Gutiérrez, quien había capturado varias personas a su paso por las estancias Cerro Argentino y San Segundo de Guillermo Castro, aunque la mayoría serán luego liberados. La columna sigue al día siguiente en dirección Norte, pasando por la estancia La Blanca de Tellaguerry haciendo noche en El Carmelo (o Friedrichstadt) de Carlos Helmich, donde capturan a cuatro personas que acababan de llegar a la misma. El día 5 de enero envía varias patrullas a los alrededores, en las que captura armas y algunos peones huidos. Al día siguiente envía otra patrulla a la estancia La Herradura de B. Bezunartea a devolverle algunos elementos que le había robado un prisionero capturado días antes de nombre Olivares y trae otro prisionero. El día 9 de enero se retira de la estancia de Carlos Helmich hacia Las Heras, dando por terminado el accionar de la columna. 


\section{Reflexiones finales}

A partir de los primeros resultados que se obtuvieron de la creación del SIG Patagonia Rebelde y las investigaciones sistemáticas sobre las huelgas de peones rurales en el noreste de Santa Cruz y su influencia en el mundo rural, se ha podido avanzar en varios aspectos. Se amplió el conocimiento de cómo afectó la huelga a la parte noreste de la provincia de Santa Cruz, en especial a algunos lugares - como los alrededores de Caleta Olivia (Zubimendi et al., 2015) — para los que existían muy escasos antecedentes. Permitieron además, realizar una detallada reconstrucción temporal de los eventos o sucesos ocurridos en un amplio territorio a partir de la sistematización de datos provenientes de fuentes dispersas, confusas e incluso contradictorias, que por medio de su integración pudo ser puesta en contexto. También fue posible ampliar la información sobre la extensión de la huelga y el movimiento de algunos de los actores involucrados. Los resultados parciales obtenidos hasta la fecha constituyen un avance con respecto a otras reconstrucciones del accionar de los huelguistas. En este sentido, hemos logrado un mayor grado de detalle en cuanto a la precisión espacial y temporal de la extensión y secuencia de sucesos de la huelga. También incorporamos un corpus documental mayor, principalmente, por ejemplo, al poder contar con el Diario de Guerra del Ejército. En este momento, se halla en análisis el expediente judicial 7644 iniciado en el año 1919 el cual incluye todas las instrucciones realizadas en el marco de las huelgas de los años 1920 y 1921 . Sin duda, a partir de las mismas será posible ampliar aún más los estudios sobre varios aspectos de estos sucesos. Esto, sumado a la minuciosa identificación de los establecimientos ganaderos y sus dueños o administradores hacia el año 1921, nos ha permitido establecer con mayor precisión la secuencia espacial y temporal del movimiento, tanto de los huelguistas como del Ejército Argentino.

Los estudios abarcan también la recuperación de la memoria de la ubicación de ciertos sucesos o eventos que se habían perdido a lo largo de los años. En especial aquellos donde estuvieron los huelguistas, las fuerzas represivas y donde se produjeron muertes, contrastando las diferentes informaciones y analizando aquellos que presentan datos contradictorios o inconsistentes, lo que permite acercarnos a una evaluación más objetiva de los sucesos que ocurrieron mayormente en localizaciones aisladas y lejos de cualquier centro urbano o poblado. Ese fue el motivo inicial por el cual se construyó la base de datos documental y el SIG Patagonia Rebelde, lo que posteriormente ha permitido construir cartografías temáticas específicas relacionadas. Otra potencialidad que esta información presenta es, a futuro, realizar modelos predictivos de las rutas seguidas por los distintos actores de la huelga empleando modelos digitales del terreno y del paisaje. De esta forma se podría postular el derrotero seguido por los huelguistas, quienes se movían mayormente a caballo cortando campos. Estos modelos podrán ser en algunos casos contrastados con las fuentes documentales y cartografía de la época en la que figuren los caminos de estancias, pero en otros podrían aportar hipótesis sobre el recorrido que realizaron.

La confección de la base de datos documental ha propiciado también la organización y clasificación de la información existente, vinculándola con información geográfica, por lo que fue posible delimitar zonas en las cuales explorar la existencia de restos de campamentos de los peones en huelga o de entierros o fosas comunes (Zubimendi et al., 2017). A su vez, al incorporar a estos estudios nuevas fuentes documentales, generadas principalmente por gente de la zona, también se está contribuyendo a afianzar el vínculo entre el patrimonio inmaterial - constituido por las múltiples voces existentes sobre las huelgas de peones rurales- con las comunidades locales y el noreste de Santa Cruz. Asimismo y mediante la interacción con la Comisión de Fomento de Jaramillo y Fitz Roy, estamos en proceso de formular un itinerario turístico que incluya al SIG Patagonia Rebelde y desde el cual integrar los sucesos de la huelga de 1921 con la historia del noreste de Santa Cruz y sus actuales habitantes e instituciones, posibilitando definir 
lugares a habilitar para una actividad turística responsable que no banalice los hechos ocurridos y vincule este patrimonio inmaterial inherente a los procesos de construcción de la identidad patagónica (Ibarroule, Reynoso, Tagliorette y Sampaoli, 2010). Esto permitirá gestar una forma de dinamizar la memoria individual y de contribuir a construir la memoria social sobre las huelgas. Al mismo tiempo, permitirá generar nuevos recursos y potencialidades a las localidades de este territorio.

\section{Agradecimientos}

Hay muchas personas a quienes agradecer en este trabajo, entre ellos quisiera destacar a Eva Malinverni, Fausto Pugnaloni, Adriel Gallardo, Sebastián Toledo, Patricia Sampaoli y Diego Gobbo, quienes aportaron sus conocimientos y me ayudaron en distintas instancias. También quisiera agradecer a los evaluadores anónimos cuyos aportes mejoraron el manuscrito. Este trabajo se realizó en el marco de los proyectos de investigación "Paisajes culturales y patrimonios fragmentados en el noreste de la provincia de Santa Cruz, su rescate y puesta en valor" (PI UNPA 29/B152) e "Historia y Patrimonio Cultural: rutas turísticas e itinerarios culturales en el noreste de Santa Cruz" (PI UNPA 29/B201-1) de la Universidad Nacional de la Patagonia Austral. También formaron parte de una estadía de investigación realizada en el año 2014 en el Dipartimento Architettura Rilievo Disegno Urbanistica Storia, de la Università Politecnica delle Marche en la ciudad de Ancona (Italia), en el marco del proyecto "Nueva Tecnología y Patrimonio Poniendo en Valor Paisajes Culturales en Santa Cruz. Una Experiencia de Cooperación Entre Italia y Argentina" (IT 305). A su vez, forma parte de un convenio de cooperación con el Archivo de la Memoria durante los años 2014 y 2015. 


\section{Referencias citadas}

" Barbería, E. M. (2001). Los dueños de la tierra en la Patagonia Austral, 1880-1920. Río Gallegos: Universidad Nacional de la Patagonia Austral.

» Bayer, O. (1968a). Los vengadores de la Patagonia Trágica. Revista Todo es Historia, 14, 22-54.

" Bayer, O. (1968b). Los vengadores de la Patagonia Trágica. Revista Todo es Historia, 15, 50-89.

» Bayer, O. (1972a). Los Vengadores de la Patagonia Trágica. Los Bandoleros (Tomo I). Buenos Aires: Editorial Galerna.

» Bayer, O. (1972b). Los Vengadores de la Patagonia Trágica. La Masacre (Tomo II). Buenos Aires: Editorial Galerna.

》 Bayer, O. (1974). Los Vengadores de la Patagonia Trágica. Humillados y ofendidos (Tomo III). Buenos Aires: Editorial Galerna.

" Bayer, O. (1984). Los Vengadores de la Patagonia Trágica. El Vindicador (Tomo IV). Buenos Aires: Editorial Bruguera.

"Bayer, O. (1994). La Patagonia Rebelde. La Masacre (Tomo II). Buenos Aires: Editorial Planeta.

» Bayer, O. (2009). La Patagonia Rebelde. Coyhaique: Talleres gráficos F.U.R.I.A.

»Bohoslavsky, E. (2005). Sobre la desconcertante maleabilidad de la memoria. Interpretaciones derechistas de la "Patagonia trágica» en Argentina, 1920-1974. Cultura, Lenguaje y Representación, II, 41-58.

»Ciselli, G. (1999). Bailando al compás de la lana. El ovino como motor del desarrollo comercial de Puerto Deseado (1881-1944). Comodoro Rivadavia: Imprenta de la Universidad Nacional de la Patagonia San Juan Bosco.

"Ejército Argentino (1921-1922). Diario de guerra Regimiento No 10 de Caballería "Húsares de Pueyrredón”, Campaña de Santa Cruz, Resumen General, Año 1921/22. Archivo Nacional de la Memoria. Manuscrito inédito.

"Ferrante, B. (2009). Obreros y huelgas patagónicas: Representaciones en publicaciones santacruceñas de las primeras décadas del siglo veinte. VII Congreso Internacional Orbis Tertius de Teoría y Crítica Literaria, La Plata. En Memoria Académica, http://www.memoria. fahce.unlp.edu.ar/trab eventos/ev.3540/ev.3540.pdf (acceso: 12 de septiembre, 2017)

»Ibarroule, A., Reynoso, E., Tagliorette, A. y Sampaoli, P. (2010). Paseo temático "La Patagonia Rebelde" e "Inventario preliminar del patrimonio regional" como aporte al desarrollo local. Trabajo presentado en Jornadas Patrimonio y Desarrollo, La Plata, Argentina.

》Ibarroule, A., Tagliorette, A. y Sampaoli, P. (2011). Estancias del Noreste de la provincia de Santa Cruz. Su historia y su Patrimonio en la primera mitad del siglo XX. Río Gallegos: Ediciones UNPA edita Universidad Nacional de la Patagonia Austral.

" Maggiori, E. (2012). Los años de la Revolución en Patagonia: 1918 - 1930. Buenos Aires: Noesno Ediciones.

"Melo, W. D. 2014. Cartografía de la Patagonia Rebelde (1921). En J. A. Uboldi, G. R. Angeles, J. O. Gentili, A. M. Geraldi, W. D. Melo y M. E. Carbone (Comps.), Geotecnologías del sur argentino. Casos de estudio (pp. 45-62). Bahía Blanca: Universidad Nacional del Sur. 
» Reinoso, C. A. (1999). A pesar del viento. Caleta Olivia: Dirección General del Boletín Oficial e Imprenta.

"Sampaoli, P. e Ibarroule, A. M. (2010). Marcha Fúnebre, el recorrido de una memoria que todavía busca llenar las ausencias para contar la historia de una huelga. Trabajo presentado en XVI Congreso Internacional de Historia Oral. Entre el Pasado y el Futuro: Comprensión de la Historia y Memoria Oral, Praga, República Checa.

»Sampaoli, P., Tagliorette, A., Zubimendi, M. A., Reynoso, E., Castro, M. A., Chacoma, G. e Ibarroule, A. M. (2014). Patrimonio y turismo en el ámbito rural del noreste de la provincia de Santa Cruz. Trabajo presentado en el III Encuentro de Investigadores de la Patagonia Austral, Río Gallegos, Argentina.

"Santos, C. (2012). Facón Grande y otros 16 relatos. Puerto Deseado: Editorial Piedra Buena.

"Suárez Samper, R. (2010). Mi Patagonia. Entre recuerdos y olvidos. Comodoro Rivadavia: Vela al Viento. Ediciones Patagónicas.

» Tagliorette A., Sampaoli, P., Reynoso, E., Zubimendi, M. A., Castro, M. A. y Chacoma, G. (2016). Paisajes culturales y patrimonios fragmentados en el Noreste de la provincia de Santa Cruz, su rescate y puesta en valor. Informe final PI 29/B/152/1. Manuscrito inédito.

» Tirachini, J. B. (1955). Mi Labor de Medio Siglo en la Patagonia. Buenos Aires: Ediciones Hipocampo.

"Zubimendi, M. A., Sampaoli, P. y Reynoso, E. (2015). Reconstrucción de los sucesos ocurridos durante la huelga de 1921 en la zona de Caleta Olivia (Noreste de Santa Cruz) mediante un Sistema de Información Geográfica (SIG). Trabajo presentado en XV Jornadas Interescuelas/Departamentos de Historia, Comodoro Rivadavia, Argentina.

"Zubimendi, M. A., Sampaoli, P., Reynoso, E. y Tagliorette, A. (2017). Campamento Cañadón del Carro. Primeros estudios para determinar la ubicación del último hito de los huelguistas rurales del año 1921 en el noreste de Santa Cruz. Trabajo presentado en las X Jornadas de Arqueología de la Patagonia, Puerto Madryn, Argentina.

» Zubimendi, M. A., Sampaoli, P. y Tagliorette, A. (en prensa). La Patagonia Rebelde en el noreste de Santa Cruz: la recuperación de la memoria y la búsqueda de las huellas de los peones rurales en huelga. Revista de Arqueología Histórica Argentina y Latinoamericana.

» Zubimendi, M. A., Tagliorette, A., Sampaoli, P., Pugnaloni, F., Malinverni, E., Carlorosi, C., Reynoso, E., Castro, M. A. y Chacoma, G. (2014). Construcción de una base de datos geográfica de los sucesos de la huelga de 1921 en el Departamento Deseado, Provincia de Santa Cruz. Trabajo presentado en el III Encuentro de Investigadores de la Patagonia Austral, Río Gallegos, Argentina. 